\title{
High-Precision GC-MS Analysis of Atmospheric Polycyclic Aromatic Hydrocarbons (PAHs) and Isomer Ratios from Biomass Burning Emissions
}

\author{
Prashant Rajput, Manmohan Sarin*, Ramabadran Rengarajan \\ Geosciences-Division, Physical Research Laboratory, Ahmedabad, India. \\ Email: sarin@prl.res.in \\ Received February 19 $9^{\text {th }}, 2011$; revised March $25^{\text {th }}, 2011$; accepted April $27^{\text {th }}, 2011$.
}

\begin{abstract}
This manuscript describes an analytical method for the quantitative determination of 16-polycyclic aromatic hydrocarbons (PAHs) using accelerated solvent extraction (ASE), followed by purification on a silica cartridge, and subsequent measurement by gas chromatograph coupled to a mass spectrometer (GC-MS). The solvent extraction parameters $(T=$ $100{ }^{\circ} \mathrm{C}, P=1500 \mathrm{psi}, t=30 \mathrm{~min}, \mathrm{~V}=30 \mathrm{ml}$ ) are optimized with dichloromethane (DCM) in order to avoid fractionation effect, thereby achieving quantitative mass recovery of PAHs. The purification of PAHs on silica cartridge eliminates the matrix effect, facilitates their enrichment from extracted solution and quantitative determination in presence of an internal-standard (Pyrene-D10). The analytical protocol has been successfully used for the quantification of 16-PAHs and their isomer ratios in atmospheric aerosols collected from northern India dominated by agriculturalwaste (post-harvest paddy and wheat residue) burning emissions. Based on the analysis of ambient aerosols, collected from different sites, the overall recovery efficiency for 2- to 3-ring PAHs is $85 \%$ and near $100 \%$ recovery for 4 - to 6-ring compounds.
\end{abstract}

Keywords: Agricultural-Waste Burning, PAHs, Accelerated Solvent Extraction, GC-MS

\section{Introduction}

Atmospheric aerosols are composed of mineral dust, inorganic constituents (sulphate and nitrate), carbonaceous matter (organic carbon and elemental carbon) and sea-salts [1-5]. Among the various components, physical adsorption characteristics of mineral dust, sea-salt (polar), and graphitic carbon (non-polar) are well understood [6-8]. These characteristics affect the high precision measurements of organic compounds and compromise their application as proxies to trace the aerosol sources and to understand their chemical reactivity with the atmospheric oxidants $\left(\mathrm{O}_{3}, \mathrm{OH}\right.$ and $\left.\mathrm{NO}_{\mathrm{x}}\right)$ [9-12]. It is, thus, essential to establish an analytical protocol for the measurements of organic compounds in atmospheric aerosols with varying mass concentration and matrix.

Analytical schemes for the quantitative determination of PAHs in environmental samples and standard reference materials are available in the literature e.g. [12-18]. However, suitability of many of these is limited to low aerosol loading. More importantly, these analytical methods have not adequately investigated the matrix effect of tarry matter (emitted from agricultural-waste burning) on mass recovery of PAHs. Therefore, development of an analytical protocol is required for the quantitative mass recovery of PAHs, by eliminating the matrix from high atmospheric loading of aerosols. We report here a quantitative method for the determination of PAHs by suitable combination of accelerated solvent extraction (ASE), followed by purification on a silica cartridge and subsequent determination on a gas chromatograph coupled to a mass spectrometer (GC-MS). The suitability of the analytical method has been ascertained from the field-based samples collected from different geographical locations in India.

The analyses of organic compounds by the conventional extraction techniques such as Soxhlet extraction and ultrasonication $[14,19,20]$, though provide their quantitative recovery, require large volume of solvents $(>100 \mathrm{~mL})$ and are often labour intensive. In spite of this, the Soxhlet extraction technique has been successfully used for the extraction of PAHs from standard reference materials (SRM-National Institute of Standards and Tech- 
nology) $[14,18]$. However, the current demand for ecofriendly environment requires minimum consumption of solvents and rapid sample preparation, without compromising the accuracy and precision. Among the two conventional techniques (ultrasonication and Soxhlet extraction), the former provides rapid sample preparation with comparatively lower consumption of solvent. An alternative extraction technique involving supercritical fluid extraction (SFE) requires longer extraction time and also suffers from the incomplete recovery of PAHs in environmental samples due to analyte-matrix interactions [21]. In contrast, the microwave-assisted solvent extraction (MASE) and the accelerated solvent extraction (ASE) approach are beneficial in terms of lower consumption of solvent and perform extraction in shorter time $[12,15$, 22-24]. However, the MASE technique requires centrifugation and filtration; thus, amounting to the loss of analyte. For the quantitative determination of PAHs, gas chromatography (GC), for its high-resolution and sensitivity, is often preferred rather than liquid chromatography (LC). Recently, the wide range of applications of GC-MS technique has been reviewed [25].

\section{Experimental Section}

\subsection{Materials and Method}

The aerosol samples $(n=17)$ analyzed in this study are collected from three different sites in India: Patiala (30.2 $\mathrm{N} ; 76.3 \mathrm{E} ; 250 \mathrm{~m}$ asl); Hisar (29.2 N; $75.7 \mathrm{E} ; 219 \mathrm{~m}$ asl) and Shillong (25.7 N; 91.9 E; $1064 \mathrm{~m}$ asl). The first two sites are located in the Indo-Gangetic Plain (IGP) whereas the third site lies in the high rainfall region of Northeastern India. The aerosol samples from Patiala and Hisar represent by and large emissions from large-scale agricultural-waste burning emissions [26-28] in the IGP. However, aerosol composition at Shillong is influenced by the long-range transport of chemical constituents from Southeast Asia. It is relevant to state that the contribution from sea-salts is insignificant at all the three sites for the sampling during Oct-May. The ambient samples were collected onto pre-combusted quartz-fibre filters (PALLFLEXTM $^{\mathrm{TM}}$ 2500QAT-UP, $20 \mathrm{~cm} \times 25 \mathrm{~cm}$ ) using high-volume samplers at a flow rate of $\sim 1.2 \mathrm{~m}^{3} \cdot \mathrm{min}^{-1}$. Soon after their retrieval, filters were covered with Al-foil, sealed in zip-lock plastic bags and stored at $4^{\circ} \mathrm{C}$ until analysis. The aerosol mass is determined gravimetrically on a high precision analytical balance (Sartorius, Model LA130S-F; $0.1 \mathrm{mg}$ ) after equilibrating the filters at relative humidity of $40 \% \pm 5 \%$ at $24 \pm 2^{\circ} \mathrm{C}$ for $10 \mathrm{hrs}$. The concentrations of elemental carbon (EC) and organic carbon (OC) are measured on a EC-OC analyzer (Model 2000, Sunset Laboratory, Forest Grove, USA) using a thermal-optical transmittance (TOT) protocol [2,9].

The HPLC grade solvents ( $\geq 95 \%$ ), dichloromethane (DCM), acetone and hexane (Chromasolv ${ }^{\circledR}$ Plus, SigmaAldrich) are used for the extraction and sample preparation. The 16-PAHs mixture (QTM PAH Mix; 47930-U, in Methylene Chloride, Supelco) and Pyrene-D10 (in methanol, 71390 Absolute Standards INC.) are used as the external and internal standards respectively. The analytical accuracy of PAHs is determined using a standard reference material (SRM-1649b), procured from the National Institute of Standards \& Technology (NIST, Gaithersburg, USA). In SRM, PAHs are extracted using the accelerated solvent extraction system (ASE 200, Dionex Corporation, Sunnyvale, USA), followed by evaporation in an evaporator (Turbo Vap LV ${ }^{\mathbb{B}}$ II, Caliper Life Sciences, Hopkinton, USA). Subsequently, extract was purified on silica-solid phase extraction cartridge (SPE; WAT020810, Waters Sep-Pak ${ }^{\circledR}, 3 c c / 500 \mathrm{mg}$ ) placed over the vacuum manifold (20 positions, WAT200606). After removal of matrix, extracts were analyzed for PAHs on a GC-MS (Agilent: 7890A/5975C). The detailed approach involving optimization of experimental conditions for the determination of 16-PAHs is described in the following sections.

\subsection{Optimization of GC-MS Parameters}

After several initial tests, a 30 min GC programme (Table 1) was adopted for the separation of 16-PAHs (listed in Table 2). Subsequently the MS conditions, especially the ion-source (filament) temperature were standardized for optimum intensity of PAHs. The PAHs were analyzed on a GC-MS in electron impact mode $(70 \mathrm{eV})$. A $1-\mu \mathrm{L}$ solution of $400 \mathrm{ppb}$ (16-PAHs; QTM mixture) spiked with $200 \mathrm{ng}$ of Pyrene-D10 (internal standard) is separated on a GC capillary column $(30 \mathrm{~m} \times 0.25 \mathrm{~mm} \times$ $0.25 \mu \mathrm{m}$; Agilent HP-5MS) at a constant flow rate of 1.3 $\mathrm{mL} / \mathrm{min}$ of helium gas and analyzed at different filament temperatures; $280^{\circ} \mathrm{C}(\mathrm{n}=4), 300^{\circ} \mathrm{C}(\mathrm{n}=4)$ and $320^{\circ} \mathrm{C}(\mathrm{n}$ $=4)$. The PAHs are identified by comparing their retention times (RT) with those for 16-PAHs standard and their quantification is achieved by comparing the peak areas with those of the internal standard (Pyrene-D10). The filament temperature at $300^{\circ} \mathrm{C}$ appeared to be the threshold for optimum relative response factors (RRF) for 16-PAHs, calculated as

$$
\mathrm{RRF}=\frac{\left\{\text { Area }_{\text {Analyte }}{ }^{*} \text { Conc }_{\text {ISTD }}\right\}}{\left\{\text { Area }_{\text {ISTD }} * \text { Conc }_{\text {Analyte }}\right\}}
$$

The ISTD stands for Internal Standard. Likewise, retention time of PAHs at varying filament temperatures (as above), are investigated, and are found to be invariable 
Table 1. Experimental parameters for the measurement of PAHs.

ASE

Parameters

Solvent

System pressure

Oven temperature

Oven heating time

Static Cycles

Nitrogen purge

Extraction Time
Optimized conditions

DCM (30 mL)

1500 psi

$100^{\circ} \mathrm{C}$

$5 \min$

3 (of 5 min each)

$60 \mathrm{~s}$

$30 \mathrm{~min}$
GC-MS

Inlet temp: $300^{\circ} \mathrm{C}$

Heating Rate

${ }^{\circ} \mathrm{C} / \mathrm{min}$

25

25

3

8

MS

\begin{abstract}
Interface temp.
\end{abstract}
Ion-source temp.

Quadrupole temp.
Temp

Hold Time

${ }^{\circ} \mathrm{C}$

Min

50

150

200

230

310

3

Table 2. Analysis of 16-PAHs in SRM 1649b, Urban Dust (n=19).

\begin{tabular}{|c|c|c|c|c|c|}
\hline \multirow{2}{*}{ 16-PAHs } & \multirow{2}{*}{$\begin{array}{c}\text { Molecular } \\
\text { weight }\end{array}$} & \multirow{2}{*}{$\begin{array}{c}\text { Retention time } \\
(\min )\end{array}$} & \multirow{2}{*}{$\begin{array}{l}\text { Detection limit } \\
\left(\mathrm{n}=12 ; \mathrm{pg} \cdot \mathrm{m}^{-3}\right)\end{array}$} & Measured Conc..$^{\S}$ & Reported Conc. \\
\hline & & & & \multicolumn{2}{|c|}{ (ng/100mg SRM) } \\
\hline Naphthalene $\{\mathrm{NAPH}\} *$ & 128 & $5.448 \pm 0.002$ & 1.9 & $90 \pm 18$ & $112 \pm 42$ \\
\hline Acenaphthylene $\{\mathrm{ACY}\} *$ & 152 & $7.000 \pm 0.004$ & 3.7 & $15 \pm 3$ & $18 \pm 3$ \\
\hline 2-Bromonaphthalene $\{2$-BrNAPH $\}$ & 206 & $7.154 \pm 0.019$ & 2.5 & NR & \\
\hline Acenaphthene $\{\mathrm{ACE}\} *$ & 154 & $7.180 \pm 0.003$ & 1.2 & $10 \pm 1$ & $19 \pm 4$ \\
\hline Fluorene $\{\mathrm{FLU}\}\}^{*}$ & 166 & $7.760 \pm 0.016$ & 1.5 & $17 \pm 2$ & $22 \pm 2$ \\
\hline Phenanthrene $\{$ PHEN $\}$ & 178 & $9.173 \pm 0.022$ & 2.3 & $373 \pm 18$ & $394 \pm 5$ \\
\hline Anthracene $\{\mathrm{ANTH}\}$ & 178 & $9.264 \pm 0.026$ & 2.6 & $44 \pm 8$ & $51 \pm 1$ \\
\hline Fluoranthene $\{\mathrm{FLA}\}$ & 202 & $12.775 \pm 0.024$ & 2.1 & $587 \pm 45$ & $614 \pm 12$ \\
\hline Pyrene $\{$ PYR $\}$ & 202 & $12.834 \pm 0.022$ & 1.6 & $481 \pm 31$ & $478 \pm 3$ \\
\hline $\operatorname{Benzo}[a]$ anthracene $\{\mathrm{BaA}\}$ & 228 & $18.275 \pm 0.041$ & 2.3 & $224 \pm 22$ & $209 \pm 5$ \\
\hline Chrysene/Triphenylene $\{\mathrm{CHRY}+\mathrm{TRIP}\}$ & 228 & $18.437 \pm 0.040$ & 1.9 & $413 \pm 28$ & $425 \pm 10$ \\
\hline Benzo $[b+j+k]$ fluoranthene $\{B[b, j, k]$ FLA $\}$ & 252 & $22.454 \pm 0.038$ & 2.4 & $923 \pm 72$ & $947 \pm 51$ \\
\hline Benzo[a]pyrene $\{\mathrm{BaP}\}$ & 252 & $23.444 \pm 0.047$ & 2.0 & $267 \pm 19$ & $247 \pm 17$ \\
\hline Indeno[1,2,3-cd]pyrene $\{\operatorname{IcdP}\}$ & 276 & $26.461 \pm 0.046$ & 1.6 & $314 \pm 20$ & $296 \pm 17$ \\
\hline Dibenzo[a,h $+\mathrm{a}, \mathrm{c}]$ anthracene $\mathrm{D}[\mathrm{ah}, \mathrm{ac}] \mathrm{ANTH}\}$ & 278 & $26.569 \pm 0.055$ & 3.6 & $49 \pm 4$ & $50 \pm 1$ \\
\hline Benzo[g,h,i]perylene $\{$ BghiP $\}$ & 276 & $26.996 \pm 0.033$ & 2.5 & $421 \pm 35$ & $394 \pm 5$ \\
\hline
\end{tabular}

*Reference values, otherwise certified values (from NIST). NR (Not reported in NIST certificate). ${ }^{\S}$ Standard deviation of the data for $\mathrm{n}=19$. 
(RT $<0.001 \%$ shift). The optimized GC-MS conditions for the determination of PAHs are listed in Table 1, and are used for the measurement of 16-PAHs in ambient aerosols. Data acquisition and processing for the GC-MS analysis is performed on a HP-Enhanced Chemstation Data System.

\subsection{Optimization of Purification Step on Silica Cartridge}

Aerosol samples contain a wide range of matrices involving mineral dust, organic carbon and elemental carbon. These matrices cause mass interferences with the analytes and affect the resolution of measurements, particularly for the measurements of PAHs on GC-MS. In this study, we have used the silica-SPE cartridge for the purification of PAHs [30]. Prior to the application of silica-SPE cartridges for purification of PAHs in aerosol samples, the elution recovery from 16-PAHs standard is investigated. Accordingly, the silica cartridges, installed over the vacuum manifold are conditioned through 10 $\mathrm{mL}$ DCM followed by $10 \mathrm{~mL}$ hexane under the vacuum ( $<340$ millibar). The cartridges are dried under normal conditions for $5 \mathrm{~min}$. Subsequently, the 16-PAHs liquid mixture of varying amount $100 \mathrm{ng}(\mathrm{n}=3), 400 \mathrm{ng}(\mathrm{n}=3)$ and, $800 \mathrm{ng}(\mathrm{n}=3)$, in $3 \mathrm{~mL}$ hexane are loaded on silica cartridges. The matrix is allowed to fall under gravity, and is discarded. The cartridges are dried again for $5 \mathrm{~min}$. The affect of cartridge drying on the PAHs mass recovery has been discussed elsewhere [30]. Subsequently, the elution of PAHs from each cartridge is performed under gravity with $3 \mathrm{~mL}, 20 \% \mathrm{DCM}$ in hexane (v/v). The eluate is evaporated to $\sim 500 \mu \mathrm{L}$ under gentle nitrogen gas stream, to which $200 \mathrm{ng}$ of Pyrene-D10 is added. The final solution is made to $1 \mathrm{~mL}$ in hexane and stored in amber coloured glass vials at $-19^{\circ} \mathrm{C}$ until analysis on GC-MS

\subsection{Optimization of Extraction Parameters on ASE}

The extraction parameters on ASE such as solvent selection, temperature and extraction time on the recovery efficiency of PAHs were investigated at a constant pressure of 1500 psi (103 bars). The extraction at 1500 psi pressure is considered to be optimal for the aerosol samples [12]. The extraction protocol was developed based on the analysis of standard reference material (NIST, SRM-1649b, Urban Dust). The toxic solvents e.g. benzene and its derivatives were not used to assess the extraction efficiency of PAHs. Furthermore, the loss of analyte during sample processing [16], if any, was checked with the low boiling point solvents e.g. DCM $\left(40^{\circ} \mathrm{C}\right)$, which not only extract PAHs quantitatively from aerosols but also can undergo rapid evaporation. Furthermore, the PAHs were also extracted from SRM in two different solvents viz. DCM $(\mathrm{n}=6)$ and DCM: Acetone $(\mathrm{n}=6 ; 1: 1 \mathrm{v} / \mathrm{v})$ at $100^{\circ} \mathrm{C}, 1500 \mathrm{psi}$ and 3 static cycles of $5 \mathrm{~min}$ each. These extracts were evaporated to 1 $\mathrm{mL}$ in evaporator $\left(<30^{\circ} \mathrm{C}\right)$ and further to near dryness by gentle nitrogen gas purge. The residue was dissolved in 3 $\mathrm{mL}$ hexane. Subsequently, the optimized protocol, described in the previous sections is used for the purification and sample preparation for PAHs analysis. The results suggest that, within the uncertainty of measurements on GC-MS, the yields for individual PAHs were equal with DCM or DCM:Acetone $(1: 1 \mathrm{v} / \mathrm{v})$. However, DCM was used for the PAHs extraction, due to its rapid evaporation (b.p. $40^{\circ} \mathrm{C}$ ) in comparison to its mixture with acetone $\left(56.3^{\circ} \mathrm{C}\right)$. The analytical accuracy (Table 2) of the protocol was determined by the SRM analysis $(n=19)$ following the protocol listed in Table 1. The molecular weight (quantification ion), retention times and the detection limits (inferred from analyses of $n=12$ blanks) for 16-PAHs are also given in Table 2.

\section{Results \& Discussion}

\subsection{Temporal Variations in $\mathbf{P} \mathbf{M}_{2.5}$ and Carbonaceous Species (OC, EC)}

The $\mathrm{PM}_{2.5}$ samples, selected for the evaluation of analytical protocol for PAHs analysis, show temporal variability in aerosol mass from 48 to $391 \mu \mathrm{g} \cdot \mathrm{m}^{-3}$. The organic and elemental carbon (OC, EC) varied from 15 to $188 \mu \mathrm{g} \cdot \mathrm{m}^{-3}$ and 2.2 to $18.5 \mu \mathrm{g} \cdot \mathrm{m}^{-3}$ respectively, whereas $\Sigma$ PAHs varied from 2 to $46 \mathrm{ng} \cdot \mathrm{m}^{-3}$. The high OC/EC ratios (range: 4 to 19) indicate the dominant contributions of carbonaceous species from biomass burning emissions (agricultural-waste burning and the wood fuel combustion) $[2,3,31]$.

\subsection{Sample Preparation for PAHs Analysis}

The elution recovery of 16-PAHs on silica-SPE cartridge is optimized using 16-PAHs standard, prior to the analysis of aerosol samples (Figure 1). The 16-PAHs standard of varying concentrations; $100 \mathrm{ng}(\mathrm{n}=3), 400 \mathrm{ng}(\mathrm{n}=3)$ and, $800 \mathrm{ng}(\mathrm{n}=3)$ in $3 \mathrm{~mL}$ hexane was eluted from the silica-SPE cartridges. A near quantitative recovery for all 16-PAHs (Figure 1) was achieved with the adopted protocol (as discussed in section 2.3). The assessment of extraction parameters (Figure 2) on ASE suggests that extraction at $100^{\circ} \mathrm{C}$ for 30 min (@1500 psi) is optimum for the quantification of PAHs in SRM. Moreover, analysis of SRM extracts $(n=12)$ for different conditions on ASE (tested range: $90^{\circ} \mathrm{C}-120^{\circ} \mathrm{C} ; 5-15$ min static cycle), suggest that though the mass recovery of PAHs 
depends on the extraction conditions, their isomers do not fractionate under these conditions on ASE (Figure 2).

A one-eighth or one-fourth portion of the quartz filter (based on Total Carbon/ Aerosol Mass) was cut into strips and loaded on the ASE. The PAHs were extracted following a developed protocol (Table 1) in $30 \mathrm{~mL}$ DCM.

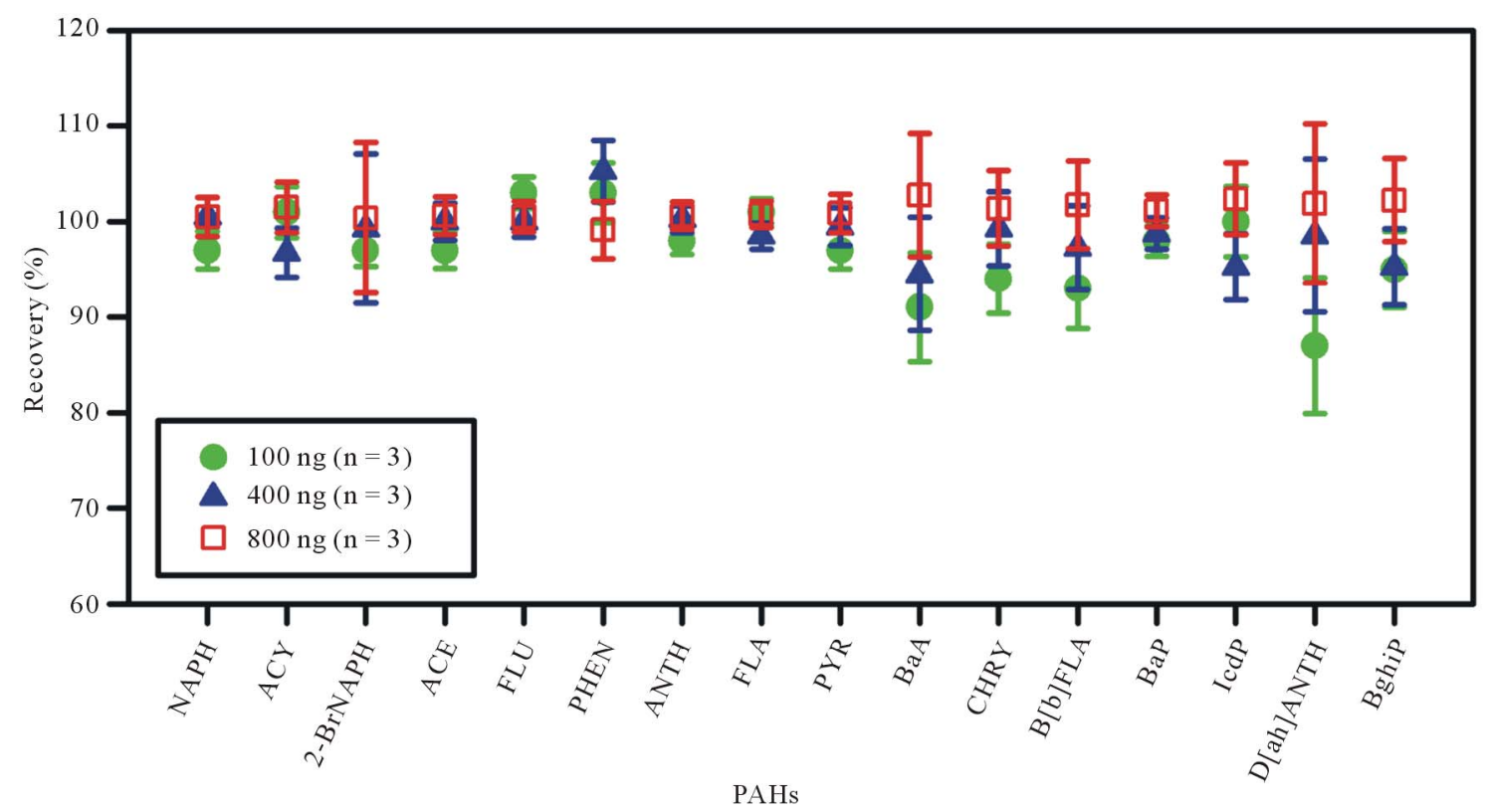

Figure 1. Recovery of 16-PAHs after purification on silica cartridge, as ascertained from a standard (QTM PAH Mix; 47930-U, in Methylene Chloride). The consistent recovery of PAHs ( 100\%) at varying concentrations of standard solution is noteworthy.

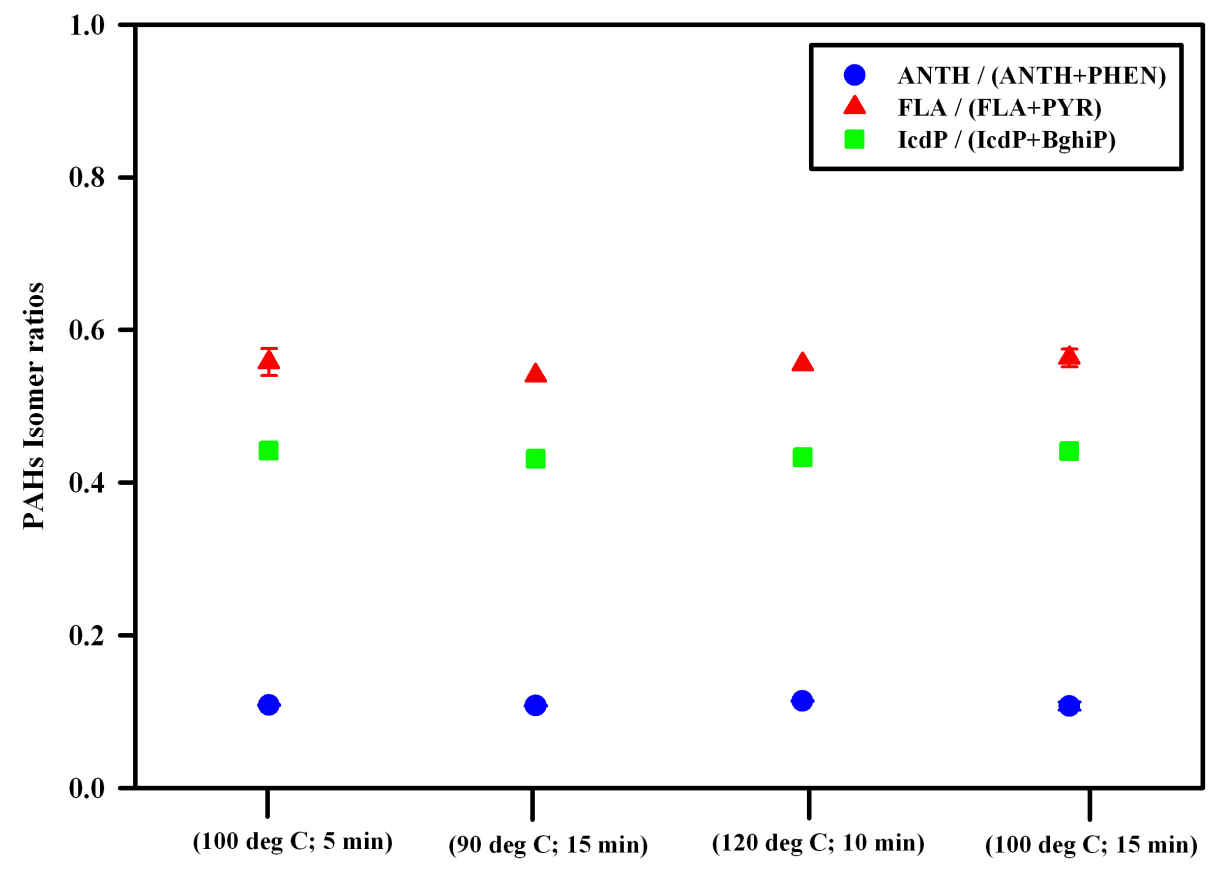

Extraction conditions on ASE

Figure 2. Replicate analysis $(n=12)$ of three different isomer pairs in SRM ascertain that accelerated solvent extraction (ASE) does not lead to fractionation of PAHs isomers. The extraction of PAHs at $100{ }^{\circ} \mathrm{C}$ for 15 min has been used as an optimized step for quantitative recovery in aerosol samples. 
The extracts were concentrated to $1 \mathrm{~mL}$ in the evaporator $\left(<30^{\circ} \mathrm{C}\right)$ and further to near dryness under a gentle stream of nitrogen gas. The residue was dissolved in $3 \mathrm{~mL}$ hexane for purification on a silica-SPE cartridge (for details refer to experimental section 2.3). The analytical accuracy for an individual PAH (except 2-BrNAPH, not reported in SRM certificate) was monitored, based on the analysis of SRM with every batch of samples. Quality-control of the data was checked by analyzing the blank filters routinely.

\subsection{PAHs Analyses on GC-MS: Evaluation of Protocol for High Aerosol Mass Loading}

The operating conditions for PAHs analysis on GC-MS are given in Table 1. The DCM based commercial standard of 16-PAHs mixture is diluted in hexane to prepare a 2 ppm stock solution. From this stock solution, seven working standards between the concentration ranges from 0 to $1500 \mathrm{ppb}$ are prepared in hexane and analyzed routinely on GC-MS. The one year record in temporal variations (insignificant for $n=35$ injections of 16-PAHs standard) of the RRF of 16-PAHs (equation 1) show the stability of GC-MS (Figure 3). Furthermore, several analyses of SRM aliquots $(\sim 100 \mathrm{mg} ; \mathrm{n}=19)$ over a period of one year, determine the analytical accuracy (Table 2). A total of $(n=17)$ ambient aerosol samples, collected from different geographical locations in India; from $\mathrm{Pa}$ tiala $(\mathrm{n}=8)$, Hisar $(\mathrm{n}=2)$ and Shillong $(\mathrm{n}=7)$, were
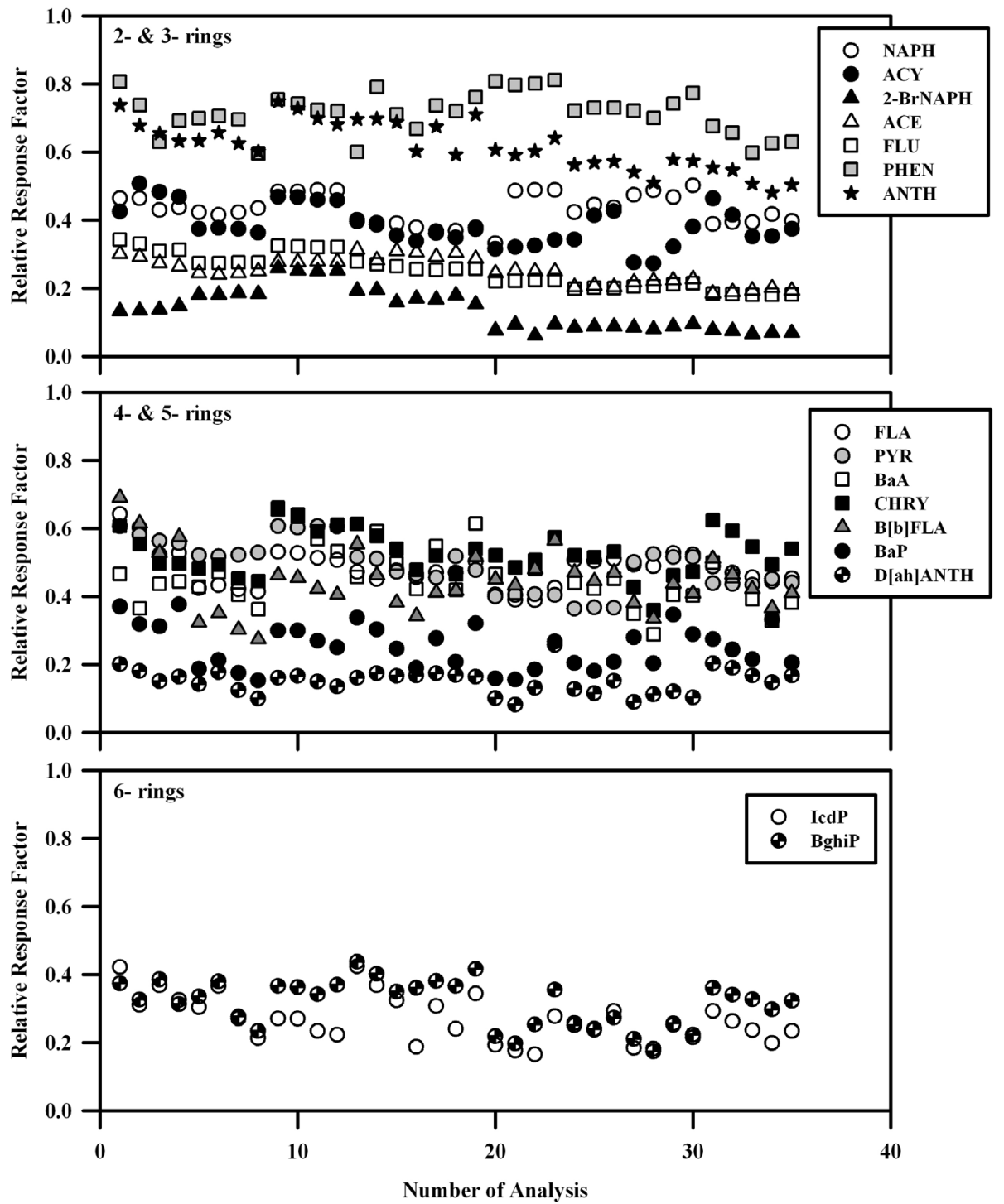

Figure 3. Time dependent analyses (n = 35; over 250 days) of 16-PAHs (QTM PAH Mix; 47930-U, in Methylene Chloride) studied to ascertain the variability in response factors on GC-MS. 
analyzed for the mass recovery of PAHs. Repeat extractions and analyses of these samples $(n=17$; Figure 4) reveal that the extraction efficiency for 2- to 3-ring PAHs is $85 \%$ whereas the recovery is $\sim 100 \%$ for 4 - to 6 -ring compounds. The overall extraction efficiency of PAHs is $97 \% \pm 2 \%$. The extraction efficiency of PAHs in aerosol samples (Figure 4) is calculated as

$$
100 * \frac{\text { PAHs recovery in first extraction }}{\text { PAHs recovery in }\{\text { first }+ \text { second }\} \text { extraction }}
$$

Analysis of several sample repeats $(n=17)$ showed that on an average the external precision of the measurements is $\pm 4 \%$. We reemphasis that these samples are representative of tarry matter and soot (along with the mineral dust), and therefore, the analytical protocol investigate the extraction efficiency of PAHs in the presence of varying matrices.

\subsection{Investigation of Loss of 2- to 3- ring PAHs During Sample Processing}

The $100 \mathrm{ng}$ of 16-PAHs mixture (QTM PAH Mix; 47930-U, in Methylene Chloride, Supelco) was spiked on pre-cleaned quartz fibre filters $(1.5 \mathrm{sq} \mathrm{cm} ; \mathrm{n}=6)$. The extraction of PAHs, followed by matrix purification and sample preparation is done in the similar way to aerosol samples. The analyses on GC-MS ensure recovery close to $100 \%$ for the individual PAHs. In contrast to the low recovery for 2- to3-ring PAHs in aerosol samples, the high recovery for all 16-PAHs from spiked filters $(\sim 100 \%)$, indicate the low concentrations of these PAHs (lighter mass) in aerosol samples lead to their low recovery.

\section{Conclusions}

An analytical method developed for the quantitative determination of PAHs from standard reference material (NIST-1649b), show analytical accuracy of $(100 \% \pm$ $15 \%$ ). The adopted protocol for the quantification of PAHs include ASE extraction with DCM at $100^{\circ} \mathrm{C}$ for 3 static cycles (of $5 \mathrm{~min}$ each) at a constant pressure of $1500 \mathrm{psi}$, followed by the matrix purification on a pre-cleaned silica cartridge and subsequent analysis on GC-MS, operated at $300^{\circ} \mathrm{C}$ as the optimum ion-source temperature. Analysis of field-based aerosol samples show the average extraction efficiency (equation 2) for 4- to 6- ring PAHs is $\sim 100 \%$. The somewhat lower recovery (mean $\sim 85 \%$ ) for 2 - to 3 - ring PAHs in the field-based samples is attributable to their lower concentrations in the aerosols. The analytical protocol, for PAHs analysis is ideal to eliminate the matrix effect from tarry matter, soot and mineral dust associated with high atmospheric loading of aerosols.

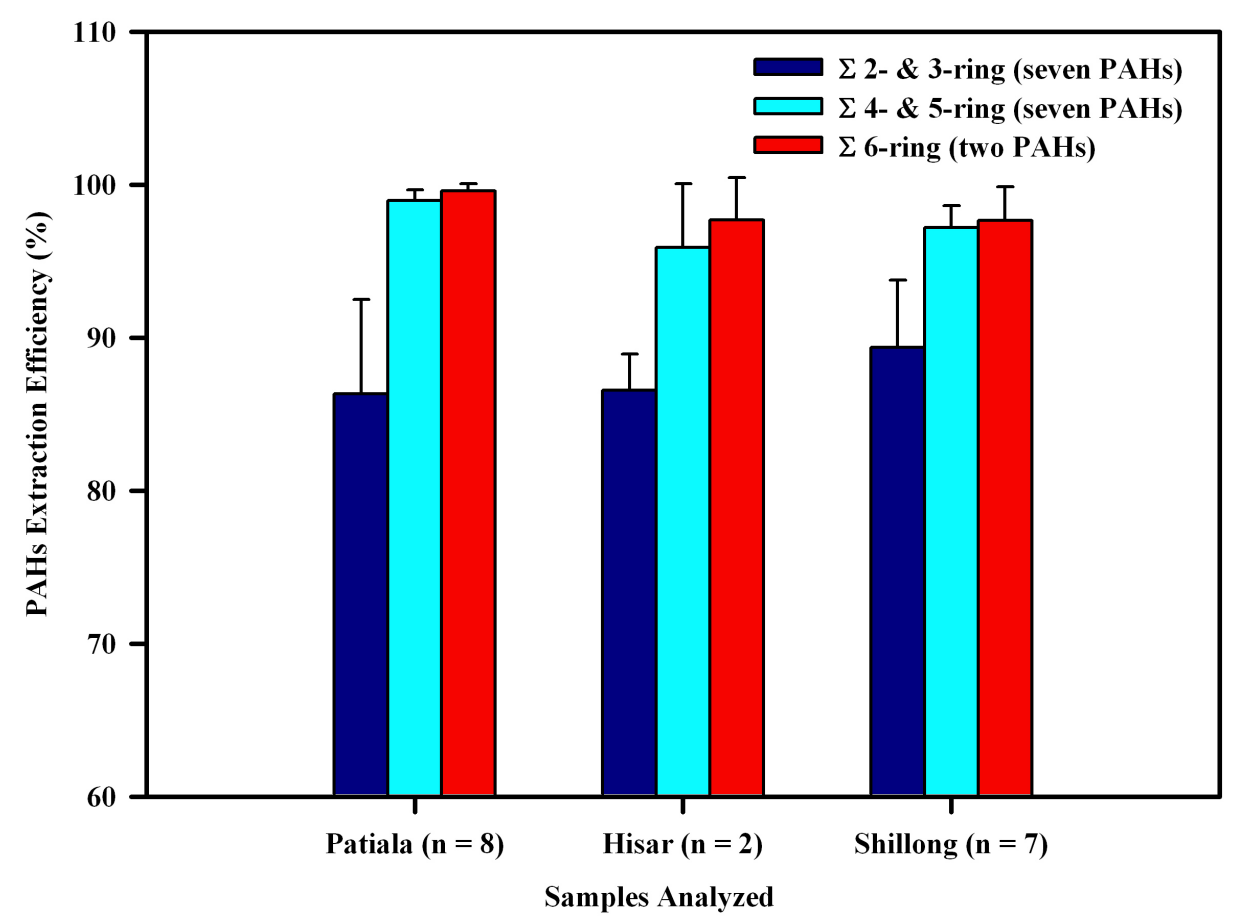

Figure 4. The extraction efficiency of PAHs, as determined in aerosol samples collected from different geographical regions. The 4- to 6- ring PAHs are recovered with $\sim 100 \%$ efficiency, whereas 2- to 3- ring PAHs show somewhat lower recovery ( 85\%) in the first extraction. 


\section{Acknowledgements}

We acknowledge the partial financial support from the ISRO-Geosphere Biosphere Programme (Bangaluru, India).

\section{REFERENCES}

[1] O. L. Mayol-Bracero, P. Guyon, B. Graham, G. Roberts, M. O. Andreae, S. Decesari, M. C. Facchini, S. Fuzzi and P. Artaxo, "Water-Soluble Organic Compounds in Biomass Burning Aerosols over Amazonia 2. Apportionment of the Chemical Composition and Importance of the Polyacidic Fraction," Journal of Geophysical Research, Vol. 107, No. D20, 2002. doi:10.1029/2001JD000522

[2] R. Rengarajan, M. M. Sarin and A. K. Sudheer, "Carbonaceous and Inorganic Species in Atmospheric Aerosols during Wintertime over Urban and High-Altitude Sites in North India," Journal of Geophysical Research, Vol. 112, No. D21307, 2007.

[3] K. Ram and M. M. Sarin, "Spatio-Temporal Variability in Atmospheric Abundances of EC, OC and WSOC over Northern India," Journal of Aerosol Science, Vol. 41, No. 1, 2010, pp. 88-98. doi:10.1016/j.jaerosci.2009.11.004

[4] J. H. Seinfeld and J. F. Pankow, "Organic Atmospheric Particulate Material," Annual Review of Physical Chemistry, Vol., 54, 2003, pp. 121-140.

doi:10.1146/annurev.physchem.54.011002.103756

[5] J. H. Seinfeld and S. N. Pandis, "Atmospheric Chemistry and Physics-From Air Pollution to Climate Change," 2nd Edition, John Wiley \& Sons, New York, 2006.

[6] S. O. Baek, M. E. Goldstone, P. W. W. Kirk, J. N. Lester and R. Perry, "Phase Distribution and Particle Size Dependency of Polycyclic Aromatic Hydrocarbons in the Urban Atmosphere," Chemosphere, Vol. 22, No. 5-6, 1991, pp. 503-520. doi:10.1016/0045-6535(91)90062-I

[7] Y. Rudich, N. M. Donahue and T. F. Mentel, "Aging of Organic Aerosol: Bridging the Gap Between Laboratory and Field Studies," Annual Review of Physical Chemistry, Vol. 58, 2007, pp. 321-352. doi:10.1146/annurev.physchem.58.032806.104432

[8] M. C. Jacobson, H. C. Hansson, K. J. Noone and R. J. Charlson, "Organic Atmospheric Aerosols: Review and State of the Science," Reviews of Geophysics, Vol. 38, No. 2, 2000, pp. 267-294. doi:10.1029/1998RG000045

[9] E. Perraudin, H. Budzinski and E. Villenave, "Analysis of Polycyclic Aromatic Hydrocarbons Adsorbed on Particles of Atmospheric Interest using Pressurised Fluid Extraction," Analytical Bioanalytical Chemistry, Vol. 383, No. 1, 2005, pp. 122-131. doi:10.1007/s00216-005-3398-7

[10] K. Miet, K. Le Menach, P. M. Flaud, H. Budzinski and E. Villenave, "Heterogeneous Reactivity of Pyrene and 1-Nitropyrene with $\mathrm{NO}_{2}$ : Kinetics, Product Yields and Mechanism," Atmospheric Environment, Vol. 43, No. 4, 2009, pp. 837-843. doi:10.1016/j.atmosenv.2008.10.041

[11] K. Miet, K. Le Menach, P. M. Flaud, H. Budzinski and E.
Villenave, "Heterogeneous Reactions of Ozone with Pyrene, 1-Hydroxypyrene and 1-Nitropyrene Adsorbed on Particles," Atmospheric Environment, Vol. 43, No. 24, 2009, pp. 3699-3707.

doi:10.1016/j.atmosenv.2009.04.032

[12] B. E. Richter, B. A. Jones, J. L. Ezzell, N. L.Porter, N. Avdalovic and C. Pohl, "Accelerated Solvent Extraction: A Technique for Sample Preparation," Analytical Chemistry, Vol. 68, No. 6, 1996, pp. 1033-1039. doi:10.1021/ac9508199

[13] G. Kiss, Z. Varga-Puchony and J. Hlavay, "Determination of Polycyclic Aromatic Hydrocarbons in Precipitation using Solid-Phase Extraction and Column Liquid Chromatography," Journal of Chromatography A, Vol. 725, No. 2, 1996, pp. 261-272. doi:10.1016/0021-9673(95)00940-X

[14] S. A. Wise, L. C. Sander, M. M. Schantz, M. J. Hays and B. A. Benner, "Recertification of Standard Reference Material (SRM) 1649, Urban Dust, for the Determination of Polycyclic Aromatic Hydrocarbons (PAHs)," Polycyclic Aromatic Compounds, Vol. 13, No. 4, 2000, pp. 419-456. doi:10.1080/10406630008233854

[15] M. M. Schantz, J. J. Nichols and S. A. Wise, "Evaluation of Pressurized Fluid Extraction for the Extraction of Environmental Matrix Reference Materials," Analytical Chemistry, Vol. 69, No. 20, 1997, pp. 4210-4219. doi:10.1021/ac970299c

[16] N. Alexandrou, M. Smith, R. Park, K. Lumb and K. Brice, "The Extraction of Polycyclic Aromatic Hydrocarbons from Atmospheric Particulate Matter Samples by Accelerated Solvent Extraction (ASE)," International Journal of Environmental Analytical Chemistry, Vol. 81, No. 4, 2001, pp. 257 - 280. doi:10.1080/03067310108044248

[17] G. Kiss, A.Gelencsér, Z. Krivácsy and J. Hlavay, “Occurrence and Determination of Organic Pollutants in Aerosol, Precipitation, and Sediment Samples Collected at Lake Balaton," Journal of Chromatography A, Vol. 774, Nos. 1-2, 1997, pp. 349-361. doi:10.1016/S0021-9673(97)00265-3

[18] S. A. Wise, B. A. Benner, S. N. Chesler, L. R. Hilpert, C. R. Vogt and W. E. May, "Characterization of the Polycyclic Aromatic Hydrocarbons from Two Standard Reference Material Air Particulate Samples," Analytical Chemistry, Vol. 58, No. 14, 1986, pp. 3067-3077. doi:10.1021/ac00127a036

[19] J. Duan, X. Bi, J. Tan, G. Sheng and J. Fu, "The Differences of the Size Distribution of Polycyclic Aromatic Hydrocarbons (PAHs) between Urban and Rural Sites of Guangzhou, China," Atmospheric Research, Vol. 78, Nos. 3-4, 2005, pp. 190-203. doi:10.1016/j.atmosres.2005.04.001

[20] M. Mandalakis, Ö. Gustafsson, T. Alsberg, A.-L. Egebäck, C. M. Reddy, L. Xu, J. Klanova, I. Holoubek and E. G. Stephanou, "Contribution of Biomass Burning to Atmospheric Polycyclic Aromatic Hydrocarbons at Three European Background Sites," Environmental Science \& Technology, Vol. 39, No. 9, 2005, pp. 2976-2982. 


\section{doi: $10.1021 / \mathrm{es} 048184 \mathrm{v}$}

[21] S. B. Hawthorne, D. J. Miller, M. D. Burford, J. J. Langenfeld, S. Eckert-Tilotta and P. K. Louie, "Factors Controlling Quantitative Supercritical Fluid Extraction of Environmental Samples," Journal of Chromatography A, Vol. 642, No. 1-2, 1993, pp. 301-317. doi:10.1016/0021-9673(93)80095-P

[22] O. Alvarez-Avilés, L. Cuadra-Rodríguez, F. GonzálezIllán, J. Quiñones-González and O. Rosario, "Optimization of a Novel Method for the Organic Chemical Characterization of Atmospheric Aerosols Based on Microwave-Assisted Extraction Combined with Stir Bar Sorptive Extraction," Analytica Chimica Acta, Vol. 597, No. 2, 2007, pp. 273-281. doi:10.1016/j.aca.2007.07.004

[23] K. K. Chee, M. K. Wong and H. K. Lee, "Microwave-Assisted Solvent Extraction of Air Particulates for the Determination of PAHs," Environmental Monitoring and Assessment, Vol. 44, Nos. 1-3, 1997, pp. 391-403. doi:10.1023/A:1005708117992

[24] L. Turrio-Baldassarri, C. L. Battistelli and A. L. Iamiceli, "Evaluation of the Efficiency of Extraction of PAHs from Diesel Particulate Matter with Pressurized Solvents," Analytical Bioanalytical Chemistry, Vol. 375, No. 4, 2003, pp. 589-595.

[25] D. L. Poster, M. M. Schantz, L. C. Sander and S. A. Wise, "Analysis of Polycyclic Aromatic Hydrocarbons (PAHs) in Environmental Samples: A Critical Review of Gas Chromatographic (GC) Methods," Analytical Bioanalytical Chemistry, Vol. 386, No. 4, 2006, pp. 859-881. doi:10.1007/s00216-006-0771-0

[26] M. Punia, V. P. Nautiyal and Y. Kant, "Identifying Biomass Burned Patches of Agricultural Residue using Satel- lite Remote Sensing Data," Current Science, Vol. 94, No. 9, 2008, pp. 1185-1190.

[27] P. K. Gupta, S. Sahai, N. Singh, C. K. Dixit, D. P. Singh, C. Sharma, M. K. Tiwari, R. K. Gupta and S. C. Garg, "Residue Burning in Rice-Wheat Cropping System: Causes and Implications," Current Science, Vol. 87, No. 12, 2004, pp. 1713-1717.

[28] K. V. S. Badarinath, T. R. K. Chand and V. K. Prasad, "Agricultural Crop Residue Burning in the Indo-Gangetic Plains - A Study using IRS-P6 A WiFS Satellite Data," Current Science, Vol. 91, No. 8, 2006, pp. 1085-1089.

[29] J. J. Schauer, B. T. Mader, J. T. DeMinter, G. Heidemann, M. S. Bae, J. H. Seinfeld, R. C. Flagan, R. A. Cary, D. Smith, B. J. Huebert, T. Bertram, S. Howell, J. T. Kline, P. Quinn, T. Bates, B. Turpin, H. J. Lim, J. Z. Yu, H. Yang and M. D. Keywood, "ACE-Asia Intercomparison of a Thermal-Optical Method for the Determination of Particle-Phase Organic and Elemental Carbon," Environmental Science \& Technology, Vol. 37, No. 5, 2003, pp. 993-1001. doi:10.1021/es020622f

[30] M. -X. Xie, F. Xie, Z.-W. Deng and G.-S. Zhuang, "Determination of Polynuclear Aromatic Hydrocarbons in Aerosol by Solid-Phase Extraction and Gas Chromatography-Mass Spectrum," Talanta, Vol. 60, No. 6, 2003, pp. 1245-1257. doi:10.1016/S0039-9140(03)00224-8

[31] K. Ram, M. M. Sarin and P. Hegde, "Atmospheric Abundances of Primary and Secondary Carbonaceous Species at Two High-Altitude Sites in India: Sources and Temporal Variability," Atmospheric Environment, Vol. 42, No. 28, 2008, pp. 6785-6796. doi:10.1016/j.atmosenv.2008.05.031 